\title{
La visualización y percepción geométrica del Principio de Cavalieri con el apoyo de GeoGebra 3D
}

\author{
Renata Teófilo de Sousa ${ }^{*}$ ) \\ rtsnaty@gmail.com \\ http://orcid.org/0000-0001-5507-2691 \\ Italândia Ferreira de Azevedo ${ }^{(*)}$ \\ italandiag@gmail.com \\ http://orcid.org/0000-0002-4684-5397 \\ Francisco Régis Vieira Alves ${ }^{*}$ ) \\ fregis@gmx.fr \\ http://orcid.org/0000-0003-3710-1561 \\ (*) Instituto Federal de Educação, Ciência e Tecnología do Ceará (IFCE) \\ Fortaleza, Brasil.
}

Recibido: 27/março/2021 Aceptado: 24/agosto/2021

\section{Resumen}

Este trabajo presenta los resultados de la aplicación de una secuencia didáctica orientada a construir conocimiento sobre el Principio de Cavalieri, con el aporte de la aplicación GeoGebra en su versión de aplicación para smartphones - Calculadora 3D. Para este estudio, se utilizaron como base conceptual la Teoría de las situaciones didácticas (TSD) de Guy Brousseau y la Teoría de las categorías del razonamiento intuitivo de Efraim Fischbein. El objetivo de este trabajo fue presentar una secuencia didáctica que pueda sustentar un aprendizaje efectivo del Principio de Cavalieri de GeoGebra, como una forma de asistir al estudiante en la construcción del razonamiento geométrico, a través de la visualización, percepción e intuición. Las reuniones se realizaron de forma remota, debido al escenario pandémico COVID-19. La solicitud se llevó a cabo con estudiantes de segundo año de secundaria de una escuela pública de educación vocacional ubicada en Fortaleza - CE. En resumen, se señala que el TSD y las categorías intuitivas asociadas a GeoGebra tienen un gran potencial para estimular la evolución del pensamiento geométrico del alumno, a través del desarrollo de la percepción, la intuición y la visualización geométrica.

Palabras clave: Teoría de las situaciones didácticas. Teoría de Categorías del Razonamiento Intuitivo. Principio de Cavalieri. GeoGebra 3D.

\section{A visualização e percepção geométrica do Princípio de Cavalieri com suporte do GeoGebra 3D}

\section{Resumo}

Este trabalho apresenta os resultados da aplicação de uma sequência didática voltada para a construção do conhecimento acerca do Princípio de Cavalieri, com o aporte do aplicativo GeoGebra em sua versão de aplicativo para smartphones - Calculadora 3D. Para este estudo foi utilizada como base conceitual a Teoria das Situações Didáticas (TSD), de Guy Brousseau e a Teoria das Categorias do Raciocínio Intuitivo, de Efraim Fischbein. O objetivo deste trabalho foi apresentar uma sequência didática que possa subsidiar uma aprendizagem efetiva do Princípio de Cavalieri a partir do GeoGebra, como forma de auxiliar o aluno na 
construção do raciocínio geométrico, por meio da visualização, percepção e intuição. Os encontros ocorreram de forma remota, devido ao cenário da pandemia COVID-19. A aplicação ocorreu com alunos do $2^{\circ}$ ano do Ensino Médio de uma escola pública de educação profissional situada em Fortaleza - CE. Em síntese, aponta-se que a TSD e as categorias intuitivas associadas ao GeoGebra têm grande potencial para estimular a evolução do pensamento geométrico do aluno, por meio do desenvolvimento da percepção, intuição e visualização geométrica.

Palavras-chave: Teoria das Situações Didáticas. Teoria das Categorias do Raciocínio Intuitivo. Princípio de Cavalieri. GeoGebra 3D.

\title{
Visualization and geometric perception of the Cavalieri Principle supported by GeoGebra 3D
}

\begin{abstract}
This work presents the results of the application of a didactic sequence aimed at the construction of knowledge about the Cavalieri's Principle, with the contribution of the GeoGebra app in its version of application for smartphones - 3D Calculator. For this study, Guy Brousseau's Theory of Didactic Situations (TSD) and Efraim Fischbein's Theory of Categories of Intuitive Reasoning were used as conceptual basis. The objective of this work was to present a didactic sequence that can support an effective learning of Cavalieri's Principle from GeoGebra, as a way to assist the student in the construction of geometric reasoning, through visualization, perception and intuition. The meetings took place remotely, due to the pandemic scenario COVID-19. The application took place with 2nd year high school students from a public vocational education school located in Fortaleza CE. In summary, it is pointed out that the TSD and the intuitive categories associated with GeoGebra have great potential to stimulate the evolution of the student's geometric thinking, through the development of perception, intuition, and geometric visualization.
\end{abstract}

Keywords: Theory of Didactic Situations. Theory of Categories of Intuitive Reasoning. Cavalieri's Principle. GeoGebra 3D.

\section{Introdução}

A Geometria - Plana, Espacial e Analítica - faz parte do componente curricular do Ensino Médio, sendo requisito para a evolução cognitiva dos estudantes nesta etapa de ensino. Segundo a Base Nacional Comum Curricular (BNCC) as habilidades necessárias para uma compreensão global da Geometria referem-se à interpretação, construção de modelos, resolução e formulação de problemas matemáticos envolvendo noções, conceitos e procedimentos espaciais (BRASIL, 2018). A Geometria mesmo com seu caráter visual e concreto, pois vários objetos do cotidiano envolvem-na, ainda é uma área em que o aluno do Ensino Médio enfrenta dificuldades na assimilação, sendo isto apontado por autores como Alves e Borges Neto (2011; 2012), Oliveira e Leivas (2017), Cunha e Aguiar (2019).

Com relação ao objeto matemático em estudo neste artigo - o Princípio de Cavalieri - há uma problemática existente no processo de ensino e aprendizagem, onde este assunto é apresentado de forma pronta, mecanizada, não explorando a visualização e a percepção 
necessárias para seu entendimento, em algumas ocasiões por falta de aprofundamento por parte do docente. Segundo Paterlini (2010) o Princípio de Cavalieri é comumente apresentado sem demonstração, como forma de furtar-se dos obstáculos de se evidenciar precocemente essa teoria. As dificuldades concentram-se em uma única asserção, que é admitida como plausível mediante uma boa argumentação e explicação do professor.

Partindo desta premissa e levando em consideração a importância que o Princípio de Cavalieri possui para a compreensão do aluno sobre o cálculo de volumes de sólidos geométricos, delineamos a seguinte pergunta de pesquisa: como o aluno pode compreender e desenvolver conceitos geométricos sobre volumes utilizando o Princípio de Cavalieri, a partir de uma perspectiva de visualização e raciocínio intuitivo? Para tal, utilizou-se o aporte do GeoGebra ${ }^{1}$, por ser um software de fácil acesso e uso, sendo eficiente para o ensino de Geometria, entre outras áreas.

O GeoGebra é um recurso que vem para agregar ao professor e facilitar sua prática, sendo eficiente na apresentação de conteúdos de complexa assimilação, onde o ambiente virtual possibilita a visualização e manipulação de seus elementos e construções. Mariotti e Fischbein (1997, p. 221) trazem que "as definições das figuras geométricas básicas não são meramente convenções no campo dos fatos puramente arbitrários; a geometria elementar e os conceitos geométricos estão profundamente enraizados na experiência comum". Assim, o software tem potencial para estimular a intuição e o raciocínio geométrico do aluno, possibilitando a dedução e a interação através de experimentações sobre o conteúdo.

O objetivo deste artigo é apresentar uma sequência didática que possa subsidiar uma aprendizagem efetiva do Princípio de Cavalieri a partir do GeoGebra, como forma de auxiliar o aluno na construção do raciocínio geométrico, por meio da visualização, percepção e intuição. Para tal, traz-se neste trabalho a Teoria das Situações Didáticas como norteadora da prática de ensino a ser aplicada, que busca enfatizar o protagonismo do aluno para a construção do seu próprio conhecimento.

O público-alvo que desenvolveu as atividades propostas neste artigo foi um grupo de alunos do $2^{\circ}$ ano do Ensino Médio, de uma escola pública de ensino profissionalizante do município de Fortaleza - CE, ocorrendo em dois encontros de forma virtual.

\footnotetext{
${ }^{1}$ O GeoGebra é um software de matemática dinâmica gratuito para todos os níveis de ensino, que pode combinar geometria, álgebra, tabelas, gráficos, estatística e cálculo numa única interface. Este software foi criado em 2001 como tese de Markus Hohenwarter e a sua popularidade tem crescido desde então. Atualmente, o GeoGebra é usado em 190 países, traduzido para 55 idiomas. Para conhecer o GeoGebra acesse www.geogebra.org.
} 
Nas próximas seções abordar-se-ão aspectos históricos, epistemológicos e didáticos acerca do Princípio de Cavalieri, a Teoria das Situações Didáticas e a Teoria das Categorias do Raciocínio Intuitivo associada ao GeoGebra e sua relevância para este artigo, bem como a metodologia aplicada com seus respectivos resultados e considerações dos autores.

\section{Aspectos históricos, epistemológicos e didáticos acerca do Princípio de Cavalieri}

Bonaventura Cavalieri (1598-1647) foi um matemático e sacerdote italiano, que trouxe diversas contribuições para o desenvolvimento da Matemática, nas áreas de Trigonometria, Astronomia, Geometria e Óptica, sendo considerado um dos precursores do Cálculo Integral (HOFFMANN, 2018). Entretanto, o cerne deste trabalho concentra-se no objeto de estudo que leva seu nome, o postulado conhecido por "Princípio de Cavalieri", comumente utilizado em problemas envolvendo o cálculo do volume de sólidos.

O enunciado do Princípio de Cavalieri traz que "Dois sólidos, nos quais todo plano secante, paralelo a um dado plano, determina superfícies de áreas iguais (superfícies equivalentes), são sólidos de volumes iguais (sólidos equivalentes)" (DOLCE; POMPEO, 2005, p. 165). Vale ressaltar que apesar de a demonstração do Princípio de Cavalieri não ser de fácil compreensão para o aluno do Ensino Médio (CUNHA; AGUIAR, 2019), deve-se considerar a apresentação de exemplos práticos para ilustrá-lo e comprovar sua veracidade, proporcionando o desenvolvimento do raciocínio geométrico de forma intuitiva, com base na visualização. De acordo com Knill e Slavkovsky (2013), a visualização de demonstrações, provas e conceitos é de grande relevância para o diálogo matemático, não apenas em sua forma ilustrativa, educacional ou heurística, mas também por ter um valor prático.

As Geometrias Plana e Espacial estão diretamente relacionadas, pois os postulados de uma servem como base para a compreensão da natureza da outra. Com base nessa relação, Alves e Borges Neto (2011) apontam que o sujeito (aluno) se apoia em imagens mentais, vivenciadas no seu dia a dia com base em objetos do mundo físico para compreender a Geometria. Por outro lado, quando este sujeito passa por algum treinamento formal, esperase que ele manifeste percepções geométricas como linearidade, regularidade, profundidade das figuras. Com relação à profundidade, esta merece ser destacada, pois, apesar de exibir um viés intuitivo, em geral, no ensino de Geometria Espacial, as representações são exibidas no plano, transmitindo uma ilusória impressão de pertencimento ao espaço tridimensional.

Partindo de uma visão epistemológica, é sabido que muitos alunos apresentam dificuldades na compreensão de problemas geométricos (OLIVEIRA; LEIVAS, 2017; CUNHA; AGUIAR, 2019), por não ter habilidades de visualização e percepção de 
representações geométricas bem desenvolvidas. Oliveira e Leivas (2017, p. 110) afirmam que "a Geometria exige a atividade do olhar com o entendimento de que uma imagem desenhada em um plano é a representação de um objeto tridimensional”. Assim, nota-se que há um obstáculo a transpor, no que tange à articulação entre as dimensões bidimensionais (2D) e tridimensionais (3D), ou seja, a articulação da figura no espaço e sua representação.

Cunha e Aguiar (2019) mencionam que o excesso de pensamento algébrico dentro da geometria acaba criando barreiras cognitivas para o aluno, pois por diversas vezes tais raciocínios podem ser desconexos. É importante levar em consideração que a visualização geométrica também é um exercício que desenvolve o raciocínio do estudante, auxiliando-o na compreensão de propriedades geométricas e na resolução de problemas. Ainda segundo os autores, o Princípio de Cavalieri não é bem explorado nos livros didáticos, sendo insuficiente em diversos aspectos, como a apresentação de fórmulas prontas, por exemplo.

Didaticamente, ao explorar o Princípio de Cavalieri, os alunos poderiam desenvolver uma perspectiva diferente acerca de espaço e forma. Ao compreender geometricamente a ideia de Cavalieri e ao aceitar esses princípios como evidentes, de forma intuitiva, muitos problemas de mensuração que normalmente requerem técnicas mais avançadas de cálculo podem ser solucionados (CUNHA; AGUIAR, 2019 apud EVES, 2011).

Ponderando sobre tais aspectos, decidiu-se desenvolver uma sequência didática para trabalhar o raciocínio geométrico do aluno com base na visualização e na intuição acerca do Princípio de Cavalieri, usando o dinamismo do GeoGebra. Para este desenvolvimento, as seções seguintes exploram a Teoria das Situações Didáticas, que será utilizada para organizar a sequência didática, bem como as categorias intuitivas de Efraim Fischbein, como suporte à compreensão do raciocínio geométrico do aluno a partir do campo visual.

\section{Teoria das Situações Didáticas}

Para o desenvolvimento deste artigo adotou-se a Teoria das Situações Didáticas (TSD), de Guy Brousseau, pois esta sugere um formato para a compreensão da relação existente entre o trinômio: aluno, professor e saber, levando em consideração também o meio (milieu) em que a situação didática ocorre. Segundo Brousseau (2008) o aluno aprende ao adaptar-se a um milieu que funciona como agente causador de dificuldades, contradições e desequilíbrios. Ou seja, "o milieu é o sistema antagonista do sistema ensinado ou previamente ensinado" (INGAR, 2014, p. 69).

Ainda sobre o trinômio citado anteriormente, este é esquematizado por Brousseau (2008) como Triângulo Didático, onde cada um de seus vértices representa as relações 
existentes entre aluno-professor, professor-saber e aluno-saber. Conforme Santos e Alves (2017, p. 6), “As relações entre professor-saber, saber-aluno e professor-aluno são estabelecidas no triângulo, a partir de seus vértices, sendo estas assimétricas e conflituosas", o que nos permite inferir que a TSD possibilita uma reflexão acerca das relações entre professor, aluno e o saber estabelecidas, visando um milieu formulado propositalmente pelo professor para instigar o aluno a buscar o conhecimento, à medida que este se adapta às situações propostas. A autonomia do aluno é desenvolvida nesse sentido, por meio da tomada de decisões, da reflexão, da organização de ideias e estratégias com base em seus conhecimentos prévios. Deste modo, o aluno ao agir pode transformar as informações fornecidas em conhecimento para si mesmo, tornando-se protagonista de seu aprendizado.

Brousseau (2008) aponta que cada conhecimento está ligado, por meio da interação entre duas ou mais pessoas, a um tipo de situação e essas interações podem ocorrer por meio de um jogo, problema/desafio ou dispositivo com suas próprias regras de interação, onde o desenvolvimento da situação ocasiona a apreensão do conhecimento pelo aluno. $\mathrm{O}$ autor define que 'uma 'situação' é um modelo de interação de um sujeito com um meio determinado" (BROUSSEAU, 2008, p. 20). Assim, o termo "situações didáticas" remete aos modelos que descrevem as relações das atividades entre aluno, professor e o milieu.

A situação didática, para funcionar de maneira efetiva, deve ser resguardada no que Brousseau traz como contrato didático. Brousseau (2008) define contrato didático como um contrato verbal que determina o papel dos sujeitos - professor e aluno -, lugares e funções de todos os envolvidos na situação didática, em um sistema de obrigações cuja reciprocidade é necessária, sendo essa relação mediada pelo saber.

Segundo Brousseau (2008) a preparação de uma situação didática requer que o professor escolha um problema que instigue o aluno a pensar, provocando a interação entre o aluno e o meio. Assim, tem-se o que Brousseau chama de situação adidática, em que o aluno estabelece relação com o problema e, sem nenhum auxílio dado, o resolve a partir de seus conhecimentos prévios. Vale ressaltar que as situações adidáticas são formuladas para que coexistam com as situações didáticas, caracterizando e obedecendo a um processo didático pré-determinado por objetivos, métodos, recursos e conceitos. As quatro fases ou dialéticas de uma situação didática, sintetizadas de acordo com Brousseau (2008), são:

Situação de ação: inicialmente, é a tomada de posição diante do problema proposto, refletindo e simulando tentativas para resolvê-lo, por intermédio da interação com o milieu; 
Situação de formulação: nesta fase, há troca de informações entre os estudantes, juntamente à verbalização de ideias e conjecturas, com a utilização de uma linguagem mais adequada, no entanto, sem a obrigatoriedade do uso explícito de linguagem matemática formal;

Situação de validação: o estudante apresenta sua estratégia de solução para a turma e tenta argumentar com base em seu raciocínio, verificando se o que ele conjecturou é, de fato, válido, por meio de linguagem matemática apropriada (demonstrações);

Situação de institucionalização: a figura do professor surge para sintetizar tudo o que foi exposto nas etapas anteriores, de maneira formal e com linguagem matemática adequada, destinada a estabelecer convenções sociais e a revelar sua intenção com o problema proposto, definindo os objetos de estudo por meio da formalização e generalização.

A situação didática é pensada pelo professor para que o aluno desenvolva o saber. Além de possibilitar a participação efetiva dos alunos em suas aulas, oferece a oportunidade de que estes desenvolvam sua autonomia, construam o conhecimento, formulem estratégias e resolvam problemas de forma criativa, propiciando sua evolução intelectual. Portanto, percebe-se a situação didática algo em que prevalece a dialética da circunstância e do contexto, sendo essencial que o professor faça o elo entre suas etapas e a transposição didática como forma de garantir que os objetivos sejam atingidos na aula planejada.

A TSD apresenta momentos em que prevalece a intuição e o raciocínio implícito, como a dialética de ação e formulação, por exemplo. Em uma tentativa de apropriação dos conhecimentos, o estudante parte para seus conhecimentos prévios, buscando construir modelos mentais que o auxiliem na resolução do problema. Para uma melhor compreensão da situação didática proposta neste trabalho, a próxima seção ilustra de forma breve o conceito de intuição, sua relação com a geometria e de que forma o GeoGebra pode auxiliar o processo de intuição, percepção e visualização geométrica dos estudantes.

\section{Teoria das Categorias do Raciocínio Intuitivo e o GeoGebra}

Segundo Pais (1996) há quatro elementos fundamentais que influenciam diretamente a aprendizagem de Geometria Euclidiana, seja plana ou espacial, que são o objeto, o conceito, o desenho e a imagem mental. Com relação a estes quatro elementos é crucial aditar a semântica presente na linguagem geométrica dentro de problemas. Assim sendo, ainda segundo o autor, tais objetos e suas respectivas representações por desenho interferem no raciocínio procedimental e na construção do conhecimento geométrico do aluno.

Fischbein (1993) aponta que os objetos geométricos dispõem de dois componentes essenciais, que são o conceito e a imagem, que concebem a aprendizagem da geometria de 
maneira considerável. Ademais, a passagem da etapa de experimentação para a abstração demanda equilíbrio entre tais componentes, que por sua vez podem ser propiciados pelo uso de softwares matemáticos, como é o caso do GeoGebra, apresentado neste trabalho.

Alves e Borges Neto (2011) apontam ainda sobre a perspectiva de Fischbein que as figuras geométricas se constituem em uma entidade mental, elaboradas a partir de um raciocínio geométrico, em que uma figura é diferente tanto de sua definição formal quanto de sua imagem mental e por sua vez é apoiada em uma percepção sensorial de uma representação particular fornecida. Os autores ainda trazem que:

[...] podemos conceber e comparar o percurso da evolução do raciocínio de um aluno com um professor. O primeiro, ao conhecer um assunto pela primeira vez, ainda não apresenta familiaridade suficientemente desenvolvida para lidar com definições formais deste conteúdo. Assim, se apoiará predominantemente num raciocínio intuitivo. Ao decorrer da evolução e no avanço sucessivo de seus estágios mentais de aprendizagem, o estudante, paulatinamente, generaliza, sistematiza e sintetiza as ideias fundamentais envolvidas naquele assunto. Deste modo, o sujeito avança para um raciocínio lógico e matemático. (ALVES; BORGES NETO, 2011, p. 42).

Ou seja, o raciocínio do aluno acerca de um novo assunto parte inicialmente da intuição e, com base em suas percepções, este passa a conjecturar suas ideias, formalizandoas em uma linha de raciocínio que faça sentido para ele. Ainda no que diz respeito à intuição, Fischbein e Gazit (1984) afirmam que o termo 'intuição' significa, “basicamente, uma avaliação global, sintética, não explicitamente justificada ou predição. Tal cognição global é sentida por um sujeito como auto evidente, auto consistente, e duramente questionável" (FISCHBEIN; GAZIT, 1984, p. 2). Assim, no que tange à Geometria, os teoremas existentes são afirmações passíveis de uma demonstração, em que sua veracidade (ou não) são garantidas por uma sequência de inferências lógicas, apoiadas na estrutura que dá início ao modelo e em outros teoremas demonstrados anteriormente.

Para Fischbein (1982) a intuição ou raciocínio intuitivo em geometria pode ocorrer na resolução de problemas, posto que o aluno é instigado a analisar, experimentar, evoluir, abstrair e sistematizar para então construir seu conhecimento matemático, sendo as estruturas intuitivas componentes essenciais de toda forma de compreensão ativa e de pensamento produtivo. Nestes comportamentos ou atitudes do aluno podem ser visualizadas as dialéticas da TSD - ação, formulação e validação -, que compõem a situação adidática, fazendo um paralelo ao que Brousseau traz em sua teoria. 
Nesse sentido, Fischbein (1987) classifica a intuição em categorias, considerando a relação entre intuição e solução, sendo divididas em intuições afirmativas, conjecturais e antecipatórias, descritas abaixo na perspectiva deste autor.

As intuições afirmativas referem-se a uma representação, uma explicação ou uma interpretação diretamente aceita pelas pessoas como algo natural, evidente, intrinsecamente significativo, como por exemplo, se alguém indagar a um estudante o que é uma linha reta, muito provavelmente ele tentará desenhar uma linha reta ou ele mostrará o exemplo de uma linha bem esticada (FISCHBEIN, 1987).

Com relação às intuições conjecturais, o aspecto da solução é explícito, mas não está envolvido claramente em um esforço de resolução. Elas representam declarações sobre eventos futuros ou sobre o curso de certo evento. Esta categoria representa uma visão preliminar, global que antecede uma solução analítica e completamente desenvolvida de um problema (FISCHBEIN,1982). O autor exemplifica em sua obra Intuition and Proof:

\footnotetext{
Parece intuitivamente claro que as diagonais em um retângulo são iguais, que o caminho mais curto entre um ponto e uma linha é a perpendicular traçada do ponto à linha, etc. Ao mesmo tempo, essas afirmações podem ser provadas, embora nenhuma prova seja necessária e, na verdade, parece bastante supérfluo. (FISCHBEIN, 1982, p. 11).
}

No que tange às intuições antecipatórias, Fischbein (1982) aponta que esta categoria da intuição proporciona uma compreensão global de uma forma possível de resolver um problema e, assim, influencia e direciona as etapas de busca e construção da solução. Neste caso o aluno encontra-se "na fase de aplicação concreta de estratégias, emprego de fórmulas, elaboração de desenhos que auxiliam de modo efetivo a identificação de uma solução" (ALVES; BORGES NETO, 2011, p. 44).

Fischbein (1987) em seus estudos analisa minuciosamente o processo de ensino e aprendizagem ao afirmar que, com frequência, o aluno enfrenta dificuldades em sua aprendizagem, compreensão e resolução de problemas em níveis mais avançados, pois suas técnicas e estratégias de raciocínio são conduzidas por modelos implícitos, por vezes inadequados. Desta forma, o professor deve buscar identificar tais modelos e fornecer suporte ao aluno na correção de seus modelos mentais, para que seu raciocínio seja construído de maneira apropriada.

Nesse sentido, o software GeoGebra tem grande potencial para desenvolver a intuição e raciocínio geométrico do aluno, por meio da percepção visual. Por ser um software de geometria dinâmica com uma janela 3D disponível em sua interface, ele possibilita a visualização de figuras em um plano xyz. Conforme Alves e Borges Neto (2012) a 
exploração do GeoGebra como instrumento tecnológico possibilita a visualização de situações inimagináveis, quando restritas ao lápis e papel.

Para viabilizar a construção do raciocínio geométrico, Hohenwarter e Jones (2007) afirmam que o GeoGebra fornece uma conexão mais próxima entre o simbólico, capacidades de manipulação e visualização de CAS - Computer Algebra Systems -, bem como a mutabilidade dinâmica do DGS - Dynamic Geometry Systems - dentro de sua interface. "O GeoGebra faz isso fornecendo não apenas a funcionalidade do DGS (em que o usuário pode trabalhar com pontos, vetores, segmentos, retas e seções cônicas), mas também de CAS (em que as equações e coordenadas podem ser inseridas diretamente e as funções podem ser definidas algebricamente e depois alteradas dinamicamente), por exemplo" (HOHENWARTER; JONES, 2007, p. 127).

Mariotti e Fischbein (1997) afirmam que há uma ligação entre geometria e realidade, mas ainda assim a geometria não é uma ciência empírica. No entanto, a Geometria precisa da realidade para que sirva de modelo para demonstrar seus diversos aspectos.

É fato que a Geometria está presente em todos os lugares, o que reforça a necessidade de sua compreensão para entender o mundo que nos cerca. Assim, segundo Oliveira e Leivas (2017) é oportuno trabalhar com situações de aprendizagem que estimulem o pensamento do aluno a estabelecer relações entre figuras espaciais e suas representações planas, buscando desenvolver, a partir de suas observações, diferentes pontos de vista, construindo e interpretando suas representações.

Alves (2019) enfatiza que o uso do software GeoGebra e a visualização que este permite em suas diferentes janelas $(2 \mathrm{D}, 3 \mathrm{D}, C A S)$ e a descrição de seus elementos proporciona um cenário significativo para a aprendizagem da matemática. Já Para Scalabrin e Mussato (2020) ao manusear um objeto construído no GeoGebra 3D, as representações das possibilidades de posição deste objeto dentro do ambiente do software proporciona significado e movimento às imagens mentais que são criadas pelo aluno.

Pelo exposto nesta seção, fundamenta-se a relevância do estudo acerca da relação entre a intuição matemática e a Geometria Espacial, visto que a percepção da geometria, por meio da visualização, tem potencial para desenvolver o raciocínio geométrico do aluno, auxiliando-o na construção de modelos mentais adequados à sua evolução cognitiva. No próximo tópico, ilustra-se a aplicação da sequência didática, metodologia deste trabalho, que expõe tais ideias de forma prática. 


\section{Metodologia}

Para este artigo, adotou-se como metodologia uma pesquisa do tipo exploratória, delineada por um estudo de caso, como forma de observar as experimentações aplicadas e ancorar dados que concordam (ou refutam) as hipóteses apresentadas. Segundo Gil (2002) os resultados de um estudo de caso são apresentados como hipóteses e não como conclusões.

A pesquisa foi desenvolvida com um grupo de vinte alunos de uma escola pública de Educação Profissional do município de Fortaleza - CE. A realização das atividades ocorreu em dois encontros em horário extraclasse, em que os alunos do $2^{\circ}$ ano do Ensino Médio foram convidados a participar de um momento de experimentação com uso de geometria dinâmica por meio do software GeoGebra. Os encontros aconteceram de forma remota, devido ao cenário atual da pandemia do Novo Coronavírus (COVID-19), com uso da plataforma Google Meet. A estruturação da situação didática seguiu:

1. Apresentação da sequência didática e estabelecimento do contrato didático;

2. Disponibilização das construções no GeoGebra;

3. Manipulação das construções pelos alunos, em busca das soluções e construção do conhecimento sobre Princípio de Cavalieri.

Para a coleta de dados foram utilizados dois formulários eletrônicos, sendo um questionário inicial para sondagem da turma acerca de seus conhecimentos sobre o GeoGebra e um questionário final, para captar suas impressões e aprendizado sobre os encontros, arquivo de gravação em vídeo do momento da aplicação e registro fotográfico. Para preservar a identidade dos participantes desta aplicação, os alunos terão seus nomes representados por Aluno 1, Aluno 2, e assim sucessivamente.

As construções no GeoGebra foram disponibilizadas para os alunos, como alternativa para otimizar o tempo e focar na manipulação e compreensão de propriedades geométricas que auxiliassem na construção do conceito sobre Princípio de Cavalieri.

\subsection{Desenvolvimento da sequência didática}

$\mathrm{Na}$ dinâmica do primeiro encontro foi estabelecido o contrato didático com a turma, apresentando o conjunto de orientações para a realização dos dois momentos. Segundo Brousseau (2008), o contrato didático consiste em um conjunto de comportamentos esperados do professor e dos alunos, mediados pelo saber.

No contrato didático com a turma foi explanado que eles resolveriam uma sequência didática, componente de uma pesquisa, reforçando que a participação de todos era de grande importância. Foi solicitado que o grupo registrasse os encontros por meio de fotografias ou 
print screen da tela do celular, tanto dos cálculos anotados em seus cadernos, quanto das manipulações no GeoGebra. Os alunos foram instruídos a realizar os cálculos em seu caderno e utilizando o aplicativo, como forma de comparar e refletir sobre as respostas. Além disso, foram orientados a utilizar chat da plataforma ou microfone para dialogar, perguntar e/ou validar suas respostas. Ademais, fora explicado que eles responderiam dois formulários, sendo um questionário inicial e um final e estabelecido que todos receberiam as construções 1,2 e 3 como arquivos do GeoGebra (.ggb) via grupo no WhatsApp.

Em seguida, apresentou-se a sequência didática, como exposta no Quadro 1:

Quadro 1 - Sequência didática proposta

\begin{tabular}{|c|c|c|}
\hline $\begin{array}{l}\text { Questão 1: Dada a construção 1, } \\
\text { determine o que se pede nos itens } \\
\text { abaixo: } \\
\text { Construção 1 }\end{array}$ & $\begin{array}{l}\text { Questão 2: Dada a construção 2, } \\
\text { determine o que se pede nos itens } \\
\text { abaixo: } \\
\quad \text { Construção } 2\end{array}$ & $\begin{array}{l}\text { Questão 3: Analisando as } \\
\text { construções 1 e 2: } \\
\text { Construções } 1 \text { e 2 }\end{array}$ \\
\hline $\begin{array}{l}\text { a) Identifique as medidas das } \\
\text { arestas. } \\
\text { b) Calcule a área da base e o } \\
\text { volume desta construção. } \\
\text { c) Apresente os cálculos } \\
\text { manuscritos e depois utilizando as } \\
\text { ferramentas do GeoGebra, } \\
\text { verificando seus achados. }\end{array}$ & $\begin{array}{l}\text { a) Identifique as medidas das arestas. } \\
\text { b) Calcule a área da base e o volume } \\
\text { desta construção. } \\
\text { c) Apresente os cálculos manuscritos } \\
\text { e depois utilizando as ferramentas do } \\
\text { GeoGebra. }\end{array}$ & $\begin{array}{l}\text { a) Manipule as construções } \\
\text { utilizando as ferramentas do } \\
\text { GeoGebra. } \\
\text { b) O que estas construções têm } \\
\text { em comum? }\end{array}$ \\
\hline
\end{tabular}

Fonte: Elaborado pelos autores.

A sequência didática buscou trabalhar a situação adidática da TSD - ação, formulação e validação para solucionar as questões apresentadas, buscando o desenvolvimento de habilidades como a percepção e intuição geométrica por meio da visualização e manipulação de construções no aplicativo do GeoGebra - Calculadora 3D. De acordo com Scalabrin e Mussato (2020, pp. 439-440), “As potencialidades que o GeoGebra apresenta, com relação aos aspectos visuais, favorece meios para a experimentação com tecnologias".

Para ambientar a turma com relação ao GeoGebra, a professora projetou a tela de seu celular (Figura 1) na sala de aula remota, apresentando o aplicativo Calculadora 3D em sua versão para smartphones. Assim, mostrou algumas funcionalidades básicas do aplicativo, a janela de álgebra e a janela 3D. 
Figura 1 - Apresentação do aplicativo Calculadora 3D, para smartphones

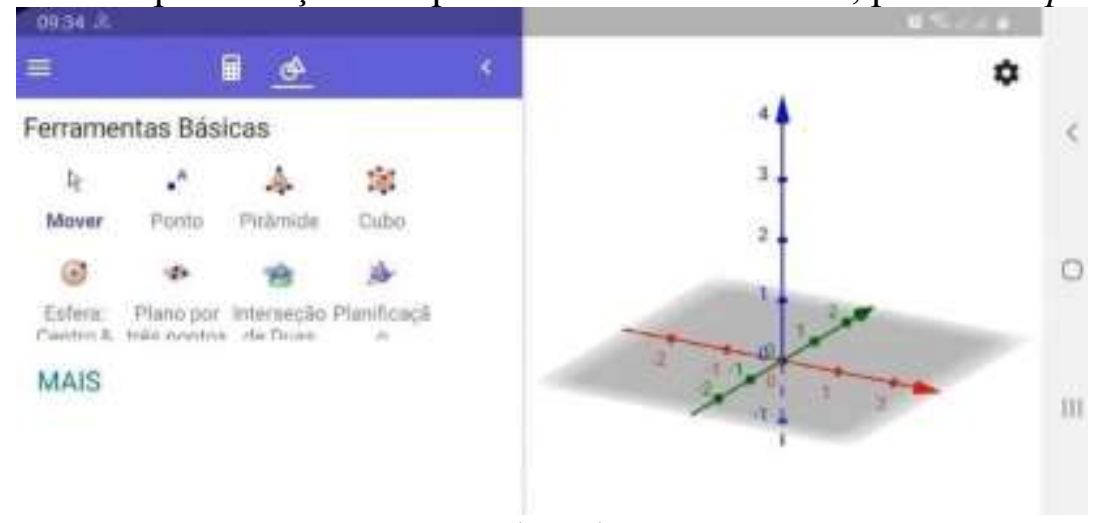

Fonte: Registro dos autores.

Na Figura 1 apresenta-se a interface inicial do aplicativo Calculadora 3D, explorado pela turma. A seguir, foi proposta a primeira questão da sequência didática, onde foi disponibilizada a construção 1 em formato (.ggb) para o grupo de alunos.

Na situação de ação, os alunos manipularam e exploraram a construção 1 apresentada dentro do aplicativo Calculadora 3D, por meio da rotação, ampliação e redução, buscando as informações necessárias para a resolução da questão proposta.

Ao indagar a turma: "Que poliedro é este?", a resposta inicial, possivelmente intuitiva, foi dizer "é um cubo, professora!", mesmo sem que as medidas dos lados tivessem sido apresentadas. Após provocações e durante a manipulação, alguns alunos do grupo perceberam que não se tratava de um cubo. O recorte de algumas falas foi:

“Não é um cubo, pois os 'lados' não são todos iguais” (Aluno 1)

"Agora eu vi que não é um cubo, pois a altura é diferente da base”" (Aluno 2)

"Parece um cubo, mas não é. É um paralelepípedo" (Aluno 3).

Segundo Fischbein (1982) a experiência mental é uma reprodução do processo prático baseado na tentativa e erro orientado para o objetivo. A prova perfeita não tem significado para a forma empírica natural de pensar, justificando porque os alunos referiramse à construção como um cubo de imediato, baseado em suas vivências, sem recorrer à uma demonstração. "Para realmente entender o que uma prova matemática significa, a mente do aluno deve passar por uma modificação fundamental" (FISCHBEIN, 1982, p. 17).

A partir da manipulação da construção, ao utilizar o comando "distância, comprimento ou perímetro", os alunos conseguiram encontrar as medidas das arestas, tanto do polígono da base quanto das arestas laterais, que correspondem à altura do prisma. Isto pode ser verificado na Figura 2, que corresponde a apresentação do Aluno 4: 
Figura 2: Apresentação do Aluno 4

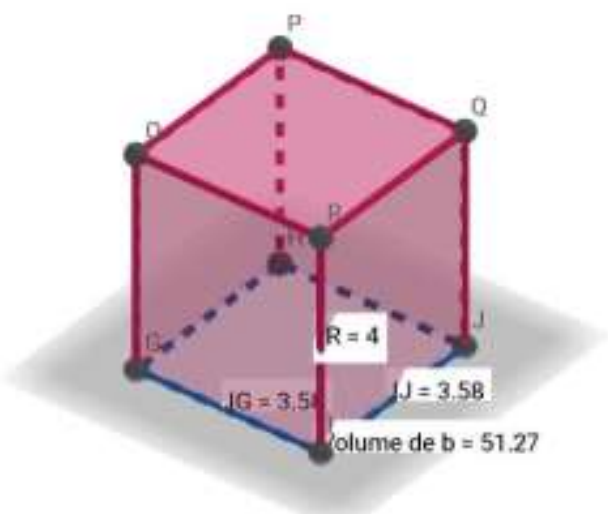

Fonte: Registro dos autores.

A partir das medidas encontradas na Figura 2, os alunos passaram a buscar os resultados da área da base e do volume da construção, com base em seus conhecimentos prévios e percepções sobre a construção, configurando a dialética de formulação da TSD.

A validação ocorreu após diálogo e participação da turma. Alguns alunos do grupo compartilharam suas ideias com os presentes, apresentando suas percepções, conjecturas e suas anotações sobre a construção, ouvindo os demais e construindo seu conhecimento.

Vale ressaltar que a validação apresentada pelo Aluno 2 estava equivocada, pois o mesmo apresentou a área da base da construção utilizando uma das arestas da base e a medida da aresta lateral $(3,58 * 4=14,32)$. Mesmo comprovando o valor desta área no GeoGebra, não era a resposta solicitada pela questão. Fischbein (1993) em sua perspectiva, aponta que no raciocínio matemático, os objetos materiais - sólidos ou desenhos - são apenas modelos materializados das entidades mentais com as quais o matemático lida. Assim, uma figura geométrica não é um mero conceito, mas sim uma imagem visual. Portanto o equívoco do Aluno 2 partiu de uma observação errônea da imagem.

Após discussão, o Aluno 3 projetou sua tela, mostrando a visão superior da construção no GeoGebra, provando que a base é um quadrado e expôs as respectivas medidas, como mostrado na Figura 3: 
Figura 3 - Visão superior da construção 1 apresentada pelo Aluno 3

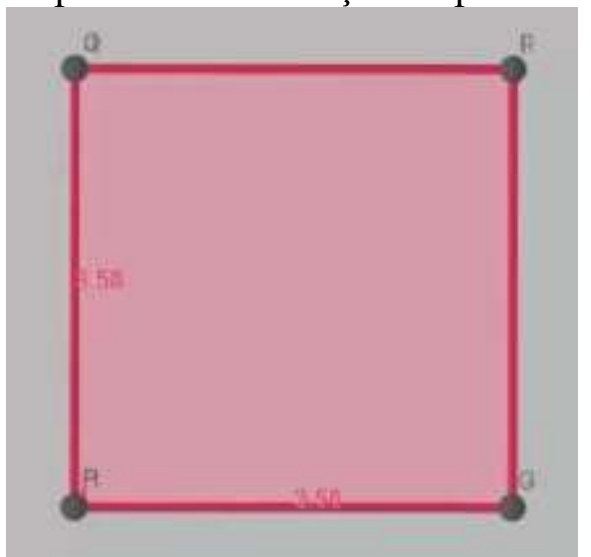

Fonte: Registro dos autores.

Alves (2020, p. 340) aponta que "o professor poderá valorizar o papel da visualização, mediante a exploração do software GeoGebra, tendo em vista a aquisição de uma cultura matemática e o delineamento de hábitos intelectuais aplicáveis em outras situações". Na Figura 4 tem-se a comparação entre os cálculos no caderno e a comprovação da resposta com base na manipulação no GeoGebra:

Figura 4 - Comparativo entre as respostas manuais e no GeoGebra - Aluno 3

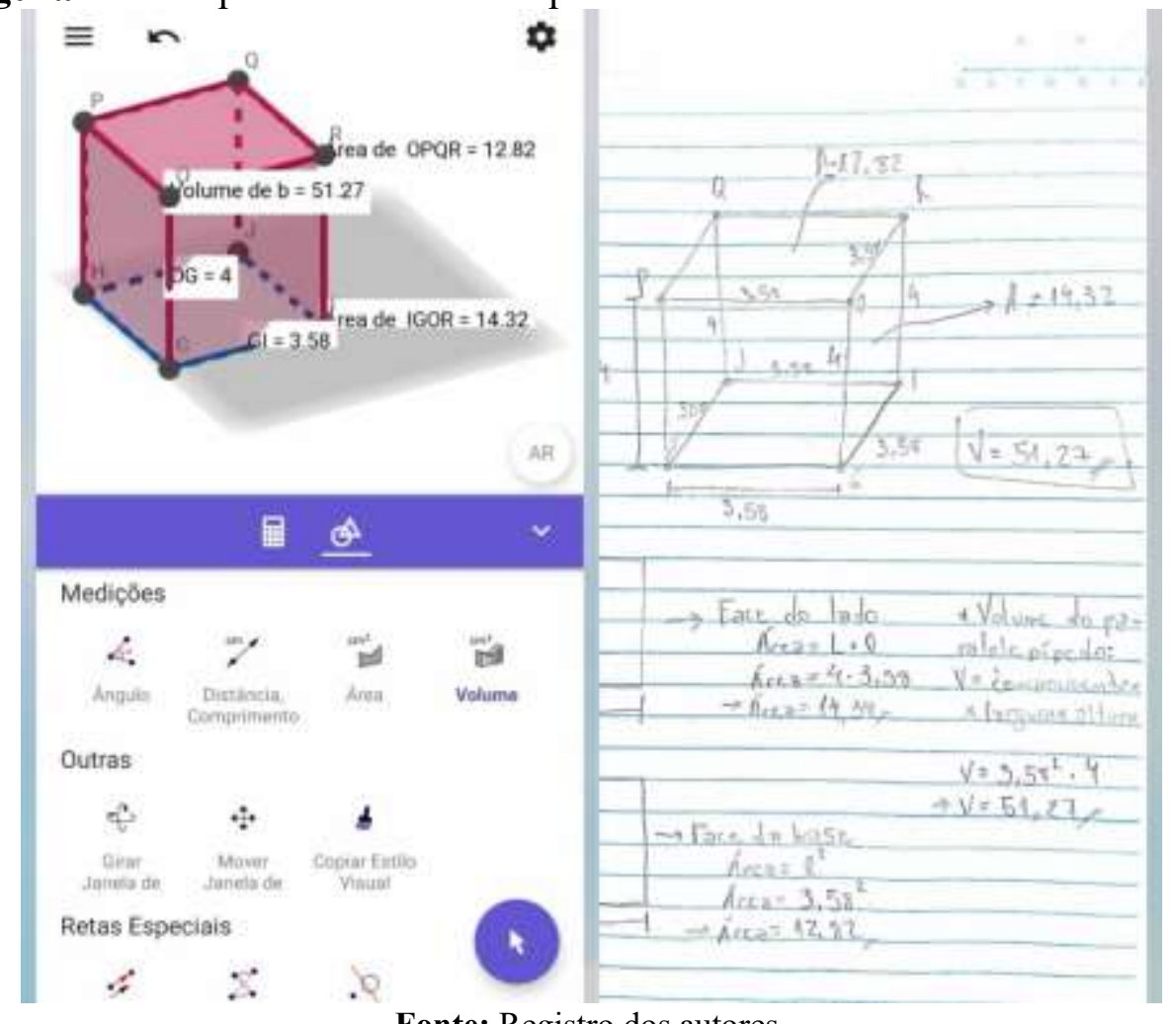

Fonte: Registro dos autores.

Na Figura 4, nota-se que o Aluno 3, para realizar os cálculos manualmente, sentiu necessidade de visualizar a imagem do paralelepípedo da construção 1, tanto que rabiscou 
um desenho para sua melhor compreensão. Neste caso, segundo Fischbein (1982) um nível de aceitação intuitiva ocorre nesta Figura 4, referindo-se ao fato de compreender a validade universal da declaração como garantida e imposta pela validade da prova.

Com relação ao segundo problema proposto, como a turma já estava familiarizada com o GeoGebra, o processo de manipulação da construção e solução da situação proposta foram otimizados. A descoberta da ferramenta de planificação causou entusiasmo e interesse. Um dos alunos usou a expressão “Que massa!” como demonstração da reação ao ver a construção em movimento, ao abrir e fechar a planificação. Nas Figuras 5 e 6 têm-se um registro desse movimento, bem como o reconhecimento do sólido formado:

Figura 5 - Movimento da planificação da construção 2

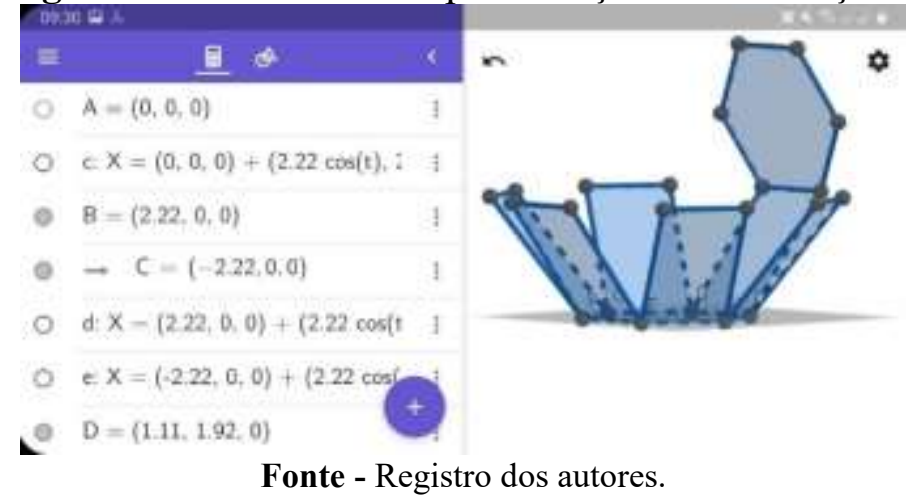

Figura 6 - Construção do prisma planificado e seu esboço 3D

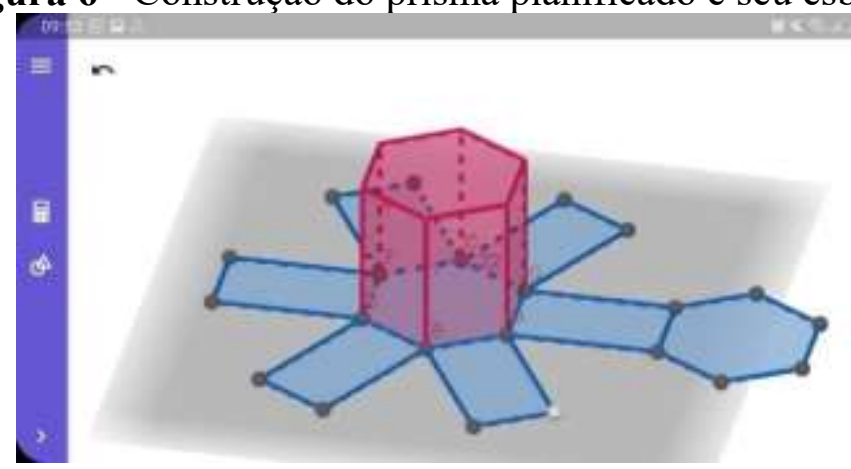

Fonte: Registros dos autores.

Ao manipular a construção 2, os alunos reconheceram-na como um prisma de base hexagonal e efetuaram os mesmos procedimentos realizados na situação da questão 1 , onde descobriram as medidas das arestas da base e das arestas laterais, configurando a dialética de ação. Deste modo, alguns alunos do grupo já recorreram ao que Fischbein (1987) classifica como intuição antecipatória, onde há uma noção das etapas a serem percorridas para solucionar o problema e da estratégia a ser utilizada para tal. 
Entretanto, na formulação, ao elaborar as conjecturas para realizar os procedimentos de cálculo manual, os alunos não lembravam como se calculava a área de um hexágono. Até que uma intuição conjectural partindo do Aluno 2 facilitou o insight do grupo:

"Um hexágono é formado por seis triângulos equiláteros. Se eu souber calcular a área de um triângulo equilátero, basta multiplicar a área por 6” (Aluno 2).

O discurso do Aluno 2 descreve a dialética de formulação, que por sua vez é marcada pela elaboração de conjecturas. Na perspectiva de Fischbein (1987) infere-se que o Aluno 2 apresentou uma intuição conjectural, pois os elementos necessários para a solução já se mostravam explícitos na construção, porém o aluno ainda não consegue visualizar a solução.

Após discussão e uma compreensão intuitiva estrutural das fórmulas matemáticas para o cálculo da área do triângulo equilátero e, posteriormente, a área do hexágono, os alunos comprovaram a veracidade de seus cálculos manuais com a calculadora (por conter aproximações decimais) e interagindo com a construção no GeoGebra, o que confere a dialética de validação, verificada na Figura 7:

Figura 7- Comparativo entre cálculo manual e resultado no GeoGebra - Aluno 3.

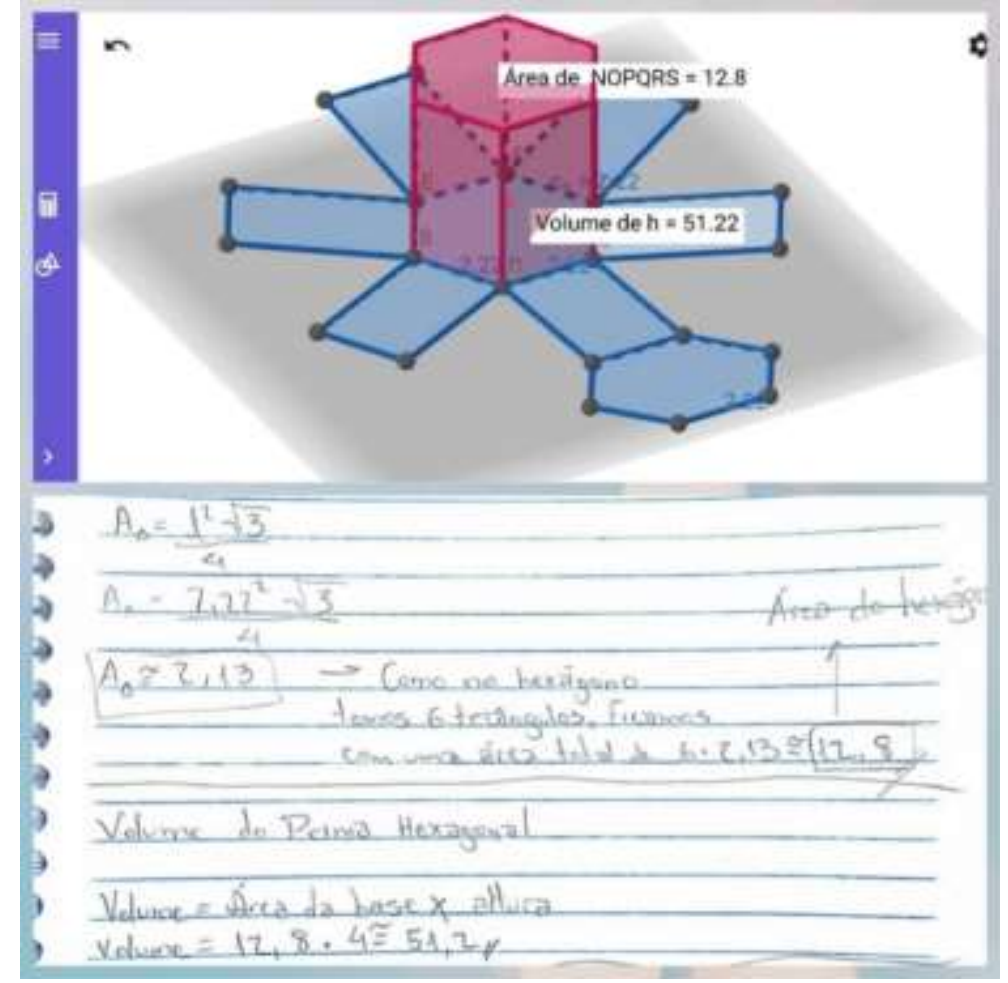

Fonte: Registro dos autores.

Fischbein (1993, p. 141) aponta que "as propriedades das figuras geométricas são impostas por, ou derivadas de definições no domínio de um determinado sistema axiomático". Partindo desse ponto de vista, uma figura geométrica tem também natureza 
conceitual. Na Figura 7, ao assumir conceitualmente que a construção corresponde a um prisma de base hexagonal, verificando as medidas das arestas da base e lateral, encontrouse por meio de um conjunto de procedimentos, valores da área da base e volume, como resultados numericamente iguais, considerando-se o arredondamento de casas decimais.

E por fim, apresentou-se a terceira questão da sequência didática, que busca estimular a concepção da generalização do Princípio de Cavalieri. Ao visualizar as construções 1 e 2 lado a lado, os estudantes foram orientados a observá-las e manipulá-las, modificando as medidas das arestas da base e da altura, conferindo sempre o mesmo valor para estas arestas em ambas as construções e observando seus resultados. Veja o exemplo desta modificação na Figura 8, onde o Aluno 2 modifica a altura:

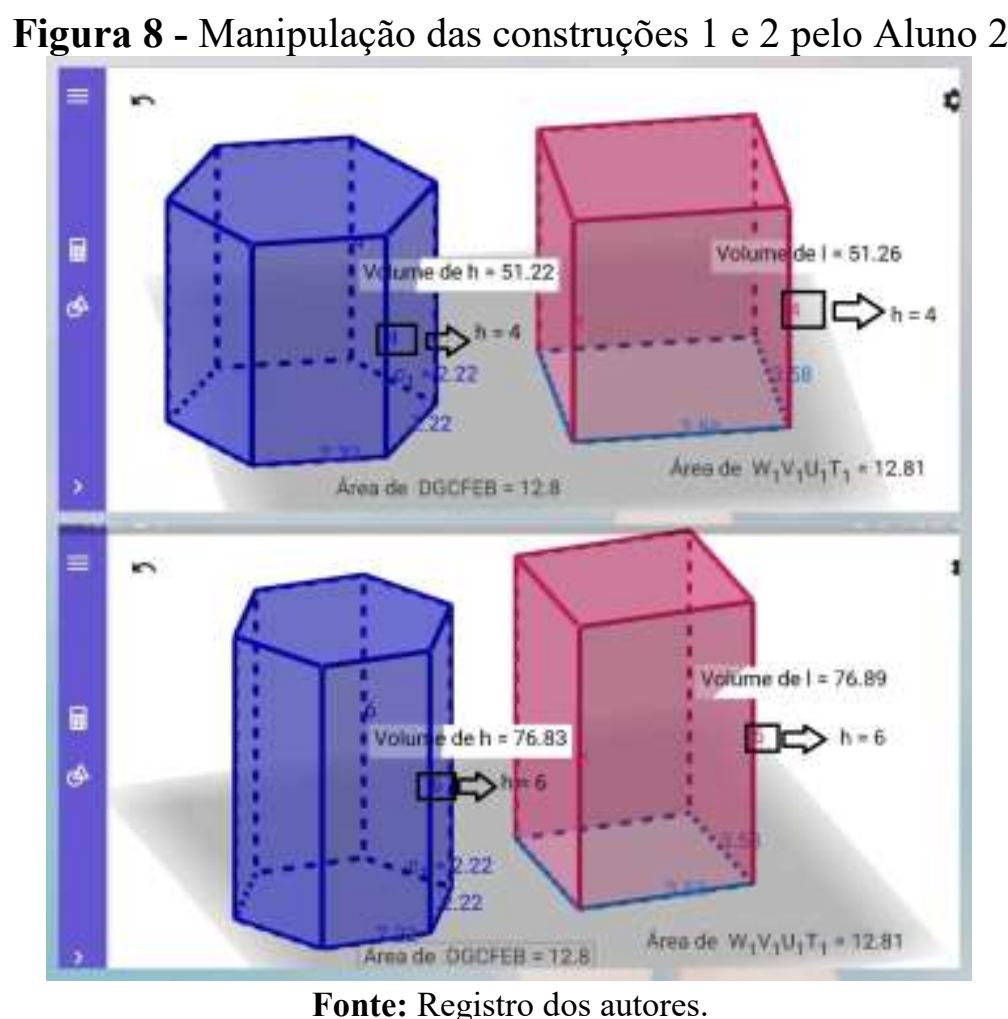

Na Figura 8 os alunos observaram que ao manipularem a medida da altura em ambas as construções, mas deixando a mesma medida nos dois sólidos, o volume também era o mesmo, com diferenças mínimas oriundas do truncamento de casas decimais. A indagação “o que estas construções têm em comum?", realizada pela professora, foi assim respondida por alguns participantes:

"Professora, a área da base é igual" (Aluno 1).

"Ah, eu lembro que na aula passada a gente tinha feito os cálculos e a altura era igual” (Aluno 2).

"Professora, a área da base é igual, a altura e o volume também!” (Aluno 3). 
Após solicitar a manipulação e modificação das medidas das duas construções, os alunos chegaram à conclusão de que "o volume sempre permanece igual". Verificadas estas observações, deu-se início a dialética de institucionalização. Para Brousseau (2008), este é o momento em que o professor sintetiza de forma significativa tudo o que foi exposto nas etapas anteriores, formalizando o caráter matemático do que foi validado pelos alunos.

A professora apresentou uma definição formal acerca do objeto proposto na questão, que no caso foi o Princípio de Cavalieri. Esta definição foi extraída do livro didático adotado pela escola, coleção Conexões com a Matemática - volume 2, ilustrado na Figura 9:

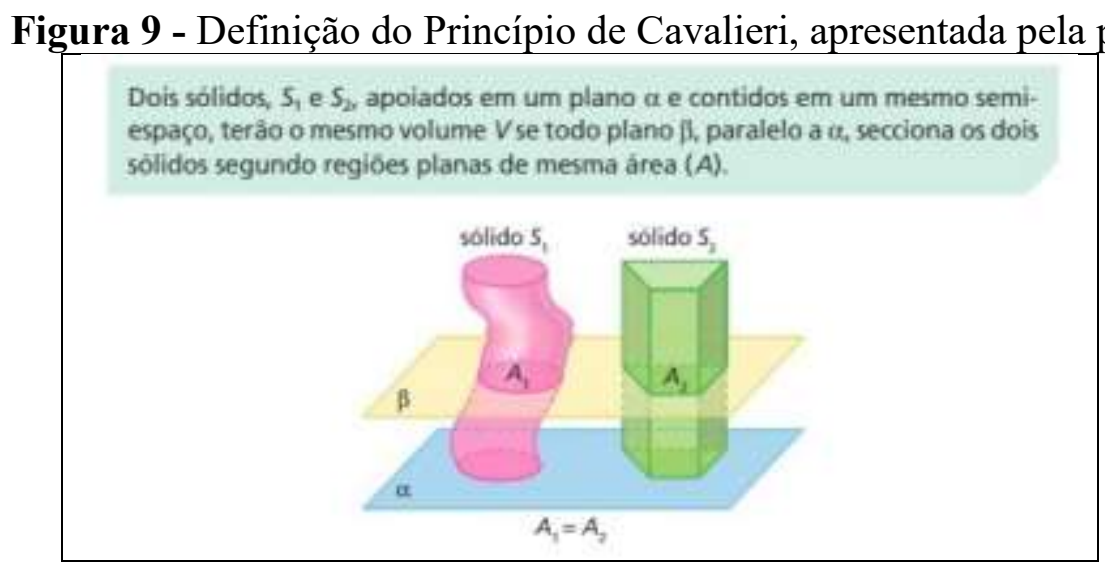

Fonte: LEONARDO, 2016, p. 117.

Após apresentar a definição de Princípio de Cavalieri, a professora relacionou com a sequência didática proposta, tendo em vista que a intenção dessa aplicação era oportunizar uma investigação, vivenciada pelos alunos, por meio da visualização e percepção viabilizada pelo GeoGebra na construção do raciocínio geométrico e compreensão deste assunto.

\section{Resultados e discussão}

Os resultados apresentados nesta seção foram coletados a partir da aplicação da sequência didática realizada nos encontros, buscando responder a nossa pergunta inicial da pesquisa, que indaga: como o aluno pode compreender e desenvolver conceitos geométricos sobre volumes utilizando o Princípio de Cavalieri, a partir de uma perspectiva de visualização e raciocínio intuitivo? Assim, a partir do registro e caracterização das impressões dos alunos sobre o uso do GeoGebra e sua utilidade para a compreensão da Geometria, as etapas do desenvolvimento das atividades mostram como os alunos alcançaram o aprendizado acerca do Princípio de Cavalieri. Após acolhida, foi aplicado o questionário inicial, que nos forneceu os seguintes resultados: 
- Na pergunta "Você conhece o GeoGebra?" 76,2\% dos alunos participantes afirmaram que sim, contra $23,8 \%$ que afirmaram não conhecer;

- Quando indagados se alguma vez utilizaram o GeoGebra para resolver exercícios de matemática, $76,2 \%$ afirmaram que nunca utilizaram, enquanto $23,8 \%$ já fizeram uso do software alguma vez;

- $81 \%$ dos alunos participantes afirmaram ter dificuldades em desenhar figuras espaciais à mão;

- $100 \%$ dos participantes afirmaram ter interesse em estudar Geometria de forma mais dinâmica.

As respostas dos alunos nos mostram que um número expressivo conhece ou já ouviu falar sobre o GeoGebra. No entanto, um número significativo de alunos nunca utilizou o software para resolução de exercícios. Pelas respostas, nota-se um interesse em aprender geometria de uma forma mais dinâmica.

Com relação ao questionário final, buscou-se uma ótica subjetiva acerca da manipulação no GeoGebra. Ao coletar a opinião dos alunos obtivemos que $75 \%$ dos alunos assinalaram a opção "Achei muito interessante", enquanto 25\% marcaram "Achei razoável”. Nenhum aluno marcou as alternativas "Achei muito difícil" e "Achei desinteressante". Assim, pode-se inferir que o GeoGebra foi um recurso que chamou a atenção e despertou o interesse de uma parcela significativa dos alunos participantes. Ao solicitar que justificassem sua resposta sobre esta manipulação, traz-se o recorte de algumas falas:

\footnotetext{
"Achei um assunto massa, uma ferramenta que ajuda bastante” (Aluno 1).

"Elabora conhecimento dinâmico, que faz o aprendizado ser efetivo" (Aluno 2).

"Eu achei um pouco dificil, pois nunca tinha usado" (Aluno 3).

"É um pouco dificil mexer no celular" (Aluno 4).

"Gostei muito da aula e consegui absorver várias coisas, eu aprendi muito" (Aluno 5).

"Ele é bem prático e simples, muito fácil de se utilizar e muito útil também" (Aluno 6).

"Achei muito interessante descobrir áreas, volumes, aresta e base” (Aluno 7).

"Nunca tinha usado, achei INCRÍVEL" (Aluno 8).

"Acho que depois que você aprende como se manuseia, é muito prático e com certeza ajuda e incentiva muito os estudos matemáticos” (Aluno 9).

"Achei bem simples, mas preciso de mais um tempo usando o programa pra aperfeiçoar foi algo novo, ficou interessante após o treinamento” (Aluno 10).
}

O relato desses alunos mostra a importância de se levar em consideração no processo de aprendizagem elementos de ordem subjetiva como atenção, interesse, emoção e até a memória, constituindo seu contexto cognitivo. Nesse sentido, os processos cognitivos na aprendizagem dos alunos constituíram-se como pressupostos teóricos originados da mobilização própria do aluno no aprender. Assim, como forma de potencializar as condições 
de aprendizagem é importante estimular uma participação ativa do aluno, buscando desenvolver seu protagonismo na construção de seu conhecimento.

Com esta aplicação e coleta de dados, foi perceptível que a situação adidática da TSD possibilitou a construção desse novo conhecimento adquirido a partir da autonomia do aluno, que passou a investigar, buscando a solução da sequência didática por meio de seus conhecimentos matemáticos. Sobre os conteúdos revisados ou aprendidos nesta aplicação, algumas das respostas coletadas mais comuns foram:

\footnotetext{
"Revisei a área do triângulo equilátero, volume do prisma e também aprendi o Principio de Cavalieri” (Aluno 1).

"Principio de Cavalieri, área do triângulo equilátero e muito mais" (Aluno 2).

“Área, volume, figuras espaciais, planificação” (Aluno 3).

“A manusear o GeoGebra” (Aluno 4).
}

Em uma análise subjetiva de suas falas, percebe-se que o GeoGebra possibilitou o desenvolvimento da capacidade de raciocínio do aluno, pois este aluno pensou, simulou e elaborou estratégias, verbalizando ideias e conjecturas e aprendendo com suas próprias percepções. Compreende-se que as categorias intuitivas foram mobilizadas e, em uma perspectiva futura, podem ser aprimoradas à medida que o uso do GeoGebra é incentivado, o que responde à pergunta desta pesquisa, bem como atende o objetivo deste trabalho.

Ao concluir que os volumes de qualquer prisma, com área da base e altura iguais, também eram iguais, os alunos atingiram o objetivo da sequência didática. Assim, a busca da solução gerou resultado satisfatório, proporcionando a construção do conhecimento.

\section{Considerações Finais}

Com esta aplicação podemos analisar que a sequência didática apresentada e explorada com o aplicativo GeoGebra - Calculadora 3D possibilitou a construção do conhecimento acerca do Princípio de Cavalieri, sendo uma abordagem de resultado satisfatório, pois as questões exploradas possibilitaram uma evolução da percepção geométrica dos alunos acerca do conteúdo matemático em questão, atingindo o objetivo da pesquisa, pois os alunos conseguiram construir um novo conhecimento a partir da exploração da associação entre o GeoGebra e as questões apresentadas.

Além disso, os depoimentos dos alunos conferem legitimidade no que diz respeito à contribuição que o GeoGebra oportunizou, através da manipulação das construções, permitindo a experimentação e exploração de conceitos dentro da Geometria Plana e Espacial, mostrando-se como uma ferramenta dinâmica e interativa. 
Vale ressaltar que as dialéticas previstas pela TSD proporcionaram uma mediação de forma orientada, onde o suporte oferecido pelo GeoGebra no que diz respeito à visualização e manipulação das construções permitiu ao aluno a estruturação de conjecturas e a exploração de conhecimentos que compuseram a identificação de intuições verificadas no desenvolvimento da aplicação.

Assim, o GeoGebra em sua versão para smartphones - Calculadora 3D - configurase em um recurso alternativo mais acessível para os alunos e que pode ser fomentado nas escolas como contributo ao ensino, não apenas sobre o Princípio de Cavalieri, mas também sobre diversos temas relacionados à Matemática.

\section{Referências}

ALVES, F. R. V. Visualizing the Olympic Didactical Situation. (ODS): Teaching Mathematics with support of GeoGebra software. Acta Didactica Naposcencia, v. 12, n. 2, p. 97-116, 2019. DOI: 10.24193/adn.12.2.8.

ALVES, F. R. V. Situações Didáticas Olímpicas (SDOs): Ensino de Olimpíadas de Matemática com arrimo no software GeoGebra como recurso na visualização. Revista Alexandria, v. 13, n. 1, p. 319-349, 2020. DOI: https://doi.org/10.5007/1982-5153.2020v13n1p319.

ALVES, F. R. V.; BORGES NETO, H. A contribuição de Efraim Fischbein para a Educação Matemática e a formação do professor. Revista Conexão, Ciência e Tecnologia, Fortaleza, v. 5, n. 1, p. 38-54, 2011. DOI: https://doi.org/10.21439/conexoes.v5i1.441.

ALVES, F. R. V.; BORGES NETO, H. Engenharia Didática para a exploração didática da tecnologia no ensino no caso da regra de L'Hospital. Educação Matemática Pesquisa, v. 14, n. 2, p. 337 - 367, 2012. Disponível em: https://revistas.pucsp.br/index.php/emp/article/view/9445/8147. Acesso em: 12 out. 2020.

BRASIL. Ministério da Educação Base Nacional Comum Curricular, 2018. Disponível em: http://basenacionalcomum.mec.gov.br/. Acesso em: 02 out. 2020.

BROUSSEAU, G. Introdução ao estudo das situações didáticas: conteúdos e métodos de ensino. São Paulo: Ática, 2008.

CUNHA, L. G.; AGUIAR, R. O cálculo de volume de sólidos usando o Princípio de Cavalieri mediado por materiais confeccionados em impressão 3D. Anais... V COLBEDUCA - Colóquio Luso-Brasileiro de Educação, v. 4, n. 1, 2019. Disponível em: https://www.revistas.udesc.br/index.php/colbeduca/article/view/17235/11264. Acesso em: 05 fev. 2021.

DOLCE, O.; POMPEO, J. N. Fundamentos da Matemática Elementar, vol. 10: geometria espacial, posição e métrica. 6 ed. São Paulo: Atual Editora, 2005. 
FISCHBEIN, E. Intuition and Proof. For the Learning of Mathematics, v. 3, n. 2, p. 918,24, nov.,1982. Disponível em: https://www.jstor.org/stable/40248127?seq=1. Acesso em: 11 nov. 2020.

FISCHBEIN, E. Intuition in science and mathematics: an educational approach. Netherlands: D. Reidel Public, Mathematics Educational Library, 1987. Disponível em: https://www.springer.com/gp/book/9789027725066. Acesso em: 10 nov. 2020.

FISCHBEIN, E. The Theory of Figural Concepts. Educational Studies in Mathematics, v. 24, n. 2, p. 139-162, 1993. Disponível em: http://www.jstor.org/stable/3482943. Acesso em 05 nov. 2020.

FISCHBEIN, E.; GAZIT, A. Does the Teaching of Probability improve probabilistic intuitions? Educational Studies in Mathematics, v. 15, n. 17, p. 1-24, 1984. Disponível em: https://www.jstor.org/stable/3482454?seq=1. Acesso em: 20 nov. 2020 .

GIL, A. C. Como elaborar projetos de pesquisa. 4 ed. São Paulo: Atlas, 2002.

HOFFMANN, M. Explorando o Princípio de Cavalieri com o GeoGebra. Dissertação de Mestrado, Universidade do Estado de Mato Grosso, Mato Grosso, MT, Brasil, 2018.

HOHENWARTER, M.; JONES, K. Ways of linking Geometry and Algebra: the case of GeoGebra. D. Küchemann (Ed.) Proceedings of the British Society for Research into Learning Mathematics, v. 27, n. 3, 2007. Disponível em: https://www.researchgate.net/publication/239830609_Ways_of_linking_geometry_ and_algebra_The_case_of_GeoGebra. Acesso em: 20 jan. 2021.

INGAR, K. V. A visualização na aprendizagem dos valores máximos e mínimos locais da função de duas variáveis reais. Tese (Doutorado em Educação Matemática) Pontifícia Universidade Católica de São Paulo - PUC, São Paulo, 2014. Disponível em: https://tede2.pucsp.br/handle/handle/11013. Acesso em: 06 out. 2020.

LEONARdo, F. M. (Org.). Conexões com a Matemática 2. 3 ed. São Paulo: Moderna, 2016.

KNILL, O.; SLAVKOVSKY, E. Illustrating mathematics using 3D printers. Cornell University, p. 1-22, 2013. Disponível em: https://arxiv.org/abs/1306.5599. Acesso em: 05 jan. 2021.

MARIOTTI, M. A.; FISCHBEIN, E. Defining in classroom activities. Educational Studies in Mathematics, n. 34, 219-248, 1997.DOI: https://doi.org/10.1023/A:1002985109323.

OLIVEIRA, M. T.; LEIVAS, J. C. P. Visualização e Representação Geométrica com suporte na Teoria de Van Hiele. Ciência e Natura, v. 39, n. 1, p. 108-117, 2017. DOI:10.5902/2179460X23170.

PAIS, L. C. Intuição, experiência e teoria geométrica. Revista Zetetiké. Ano 6, 1996. DOI: https://doi.org/10.20396/zet.v4i6.8646739.

PATERLINI, R. R. Os "Teoremas" de Cavalieri. Revista do Professor de Matemática, n. 72, p. 43-47, 2010. Disponível em: https://www.dm.ufscar.br/ ptlini/paterlini_cavalieri.pdf. Acesso em: 15 fev. 2021. 
SANTOS, A. A.; ALVES, F. R. V. A Engenharia Didática em articulação com a Teoria das Situações Didáticas como percurso metodológico ao estudo e ensino de Matemática. Revista Acta Scientiae, Canoas, v. 19, n. 3, p. 447-465, 2017. Disponível em: http://www.periodicos.ulbra.br/index.php/acta/article/view/2739/2373. Acesso em: 29 jan. 2021.

SCALABRIN, A. M. M. O.; MUSSATO, S. Uso del software GeoGebra: Análisis del proceso de aprendizaje de los conceptos de poliedro. Revista Paradigma, vol. XLI (Extra 2), p. 427-447, 2020. Disponível em: https://doi.org/10.37618/PARADIGMA.1011-2251.0.p427-447.id922. Acesso em: 01 mar. 2021.

TEIXEIRA, P. J. M.; PASSOS, C. C. M. Um pouco da Teoria das Situações Didáticas (TSD) de Guy Brousseau. Revista Zetetiké, v. 21, n. 1, p. 155-168, 2014. DOI: https://doi.org/10.20396/zet.v21i39.8646602.

Autores

Renata Teófilo de Sousa. Professora efetiva da rede estadual do Ceará. Licenciada em Ciências da Matemática pela Universidade Estadual Vale do Acaraú - UVA e Especialista em Ensino da Matemática pela mesma instituição. Atuou como bolsista e, posteriormente, como supervisora do PIBID - Programa Institucional de Bolsas de Iniciação à Docência. Atuante na rede pública como professora de Matemática e Física no nível médio.

Italândia Ferreira de Azevedo Mestra em Ensino de Matemática pelo Programa de PósGraduação em Ensino de Ciências e Matemática no IFCE, campus Fortaleza. Tem especialização em Gestão Pedagógica da Escola Básica pela UECE e Especialização em Ensino de Matemática pela Universidade Estadual Vale do Acaraú - UVA. Graduada em Licenciatura em Matemática pela UVA desde 2011 e professora efetiva pela Secretaria de Educação do Estado do Ceará, desde 2013. Tem experiência com educação à distância na função de tutora em 2015 no Centro de Educação à Distância do Ceará, localizado na cidade de Sobral- CE. Coordenou o PAPMEM - Programa de Aperfeiçoamento para professores de Matemática do Ensino Médio da região norte do Ceará. Possui experiência em formação de professores, elaboração de itens e produção de material didático.

italandiag@gmail.com

Francisco Régis Vieira Alves. Possui graduação em Bacharelado em Matemática pela Universidade Federal do Ceará (1998), graduação em Licenciatura em Matemática pela Universidade Federal do Ceará (1997), mestrado em Matemática Pura pela Universidade Federal do Ceará (2001) e mestrado em Educação, com ênfase em Educação Matemática, pela Universidade Federal do Ceará (2002). Doutorado com ênfase no ensino de Matemática (UFC - 2011). Atualmente é professor TITULAR do Instituto Federal de Educação Ciência e Tecnologia do estado do Ceará/ IFCE. Desenvolve pesquisa direcionada para o ensino do Cálculo a Várias Variáveis e sua transição interna. Atua também no Mestrado Profissional em Ensino de Ciências e Matemática (ENCIMA) - UFC. Coordenador do Programa de Pós Graduação em Ensino de Ciências e Matemática PGECM/IFCE (acadêmico). no período de 2015/2020.

fregis@gmx.fr 